\title{
Attachment Styles and Perceptions of Alcohol Consumption in a College Population
}

\author{
Jordan Lane Walker and Crystal Mata Kreitler* \\ Department of Psychology, Angelo State University, USA
}

Submission: February 02, 2018; Published: February 22, 2018

*Corresponding author: Crystal Mata Kreitler, Department of Psychology, Angelo State University, USA; Email: crystal.kreitler@angelo.edu

Abstract

The investigators sought to explore the correlation between attachment style and alcohol consumption that has been highlighted by previous researchers [1-3]. Specifically, the current study measured factors such as attachment styles, current alcohol use levels, estimated alcohol use levels of peers, motivations for consuming alcohol, and self-esteem in a college population. The current study was not able to reestablish the correlation between insecure attachment styles and increased alcohol consumption. However, alcohol consumption was found to have several significant positive correlations with social motivations, coping motivations, enhancement motivations, and estimated alcohol use of peers. Additionally, the current study found that, on average, participants estimated their peers' levels of alcohol consumption to be almost five times higher than the ramount of alcohol that they personally consumed. Among other implications discussed, the results could guide university staff members in creating underage drinking prevention initiatives.

Abbreviations: NIAAA: National Institute on Alcohol Abuse and Alcoholism; SAMHSA: Substance Abuse and Mental Health Service Administration; AUD: Alcohol Use Disorder; RQ: Relationship Questionnaire; RSES: Rosenberg Self-Esteem Scale; AUDIT: Alcohol Use Disorder Identification Test; DMQR: Drinking Motives Questionnaire-Revised

\section{Attachment Styles and Perceptions of Alcohol}

\section{Consumption in a College Population}

Alcohol is the fourth leading preventable cause of death in the United States, killing nearly 88,000 people a year and contributes to the prevalence of over 200 health conditions [4]. Additionally, negative effects of alcohol were estimated to cost the U.S. economy $\$ 223$ billion dollars in 2006 [5]. Alcohol misuse can start young and it is estimated that individuals between the ages twelve and twenty consume $11 \%$ of the alcohol in the United States [6]. In 2012, an estimated 22.2 million Americans over the age of twelve were diagnosed as having a substance abuse disorder according to the 2012 National Survey on Drug Use and Health conducted by the Substance Abuse and Mental Health Service Administration [7]. One demographic whose drinking behavior causes concerns is college students. College students report higher rates of binge drinking and a higher prevalence of driving while intoxicated than their non-college-attending peers [8]. It is thought that $20 \%$ of college students meet the criteria for an Alcohol Use Disorder (AUD). This increased level of binge drinking can result in repercussions such as academic consequences, suicide attempts, alcohol poisoning, health problems, unsafe sex, injuries, assault, sexual assault, vandalism, property damage, and involvement with the police. Because of the prevalence of substance abuse and the dangers associated with it, contributing factors to these disorders need to be studied. One of these factors is an insecure attachment style [2,3].

Palfai et al. [1] conducted research using a self-report survey and found that insecure attachment styles with a negative model of self (i.e. preoccupied and fearful attachment styles) were associated with higher alcohol consumption. They also found that these individuals experienced a greater number of drinking related consequences than did their peers, and that those drinking related consequences could not be attributed completely to the amount of alcohol the individual consumed. De Rick [2] conducted a study on patients being treated for alcoholism and found that alcoholism does not cause an insecure attachment style, but rather the attachment style was present before the individuals exhibited substance use problems. Being able to create social attachments helps reduce stress, reduce anxiety, increase mental health, and increase levels of oxytocin and it also promotes regulating behavior [2].

A couple of theories have been developed to explain the relationship between attachment style and alcohol consumption. According to one theory, when the need for social attachments goes unmet substances, such as alcohol, could be used in order to cope. A second theory has been proposed to explain the correlation between attachment style and increased levels of 
alcohol misuse. It notes that an insecure attachment style could have the evolutionary function of creating a personality of high novelty seeking, also called the sensation seeking personality trait, which would be beneficial to people in a high risk and low predictable environment. Levels of high novelty seeking are associated with low trust, high numbers of partners, perception of risk in intimacy, and infidelity. It is also associated with more experimentation with drugs and alcohol [3].

Another factor associated with alcohol use is perceptions. It is thought that perceptions of peers' drinking behavior are a causal factor for an individual's drinking behavior [9]. Research has shown that college students have a tendency to overestimate the quantity and frequency of drug use, sexual activities, and especially the alcohol consumption of their peers. This exaggerated peer norm is thought to be due to factors such as flaws in attribution processes, flaws in memory recall, and culture.

\section{Study Overview and Hypotheses}

The researchers examined a college population to determine if attachment style would be correlated with higher alcohol consumption in this demographic since majority of the studies found by the researchers were in clinical settings. The researchers hypothesized that participants who reported insecure attachment style would report greater levels of alcohol consumption than those who reported a secure attachment style (H1). The current research also sought to test the validity of the theory that individuals with insecure attachment styles were more likely to consume alcohol for coping motivations due to social needs being unmet. The researchers formed the hypotheses that participants who reported insecure attachment styles would indicate that they consume alcohol due to coping and social motivations significantly more often than participants with secure attachment styles (H2). Additionally the researchers were interested in examining if there was a difference between the perceptions of peers' drinking behaviors depending on attachment style (RQ1) and if there was a correlation between self-esteem scores and drinking motivations (RQ2).

\section{Method}

\section{Participants}

The current study recruited 188 undergraduate students at Angelo State University. Participants were offered course credit or extra credit for their participation. Forty of the data sets were omitted due to incomplete responses. The remaining participants' age ranged from 17 to $44(\mathrm{M}=20.09, \mathrm{SD}=3.47)$. The majority of the participants were women (83.8\%). Participants identified themselves as Caucasian (62.8\%), Hispanic $(24.3 \%)$, African American (6.1\%), Asian (4.1\%), Native Indian (1.4\%), and other or no answer (2.1\%). Most participants identified themselves as college freshmen (37.8\%). This is likely because research participation is a component in many freshmen level general psychology courses at Angelo State University. Only $10.8 \%$ of participants indicated they were a member of a fraternity or sorority and only $6.8 \%$ of participant indicated they were athletes. A large percentage of participants reported their grade point average to be between $3.1-3.5$ on a 4.0 scale $(45.3 \%)$.

\section{Measures}

Demographics Questionnaire: This questionnaire consisted of two sections. The first section of the questionnaire asked participants to provide their age, gender, ethnicity, and year in college. The second demographic section asked if the participants were members of a fraternity, sorority, or athletic team on campus.

Relationship Questionnaire: The 4-item Relationship Questionnaire[10] measuredattachmentstyle. Thisquestionnaire lists four statements describing how the participant might feel about his or her relationships. A sample item includes, "I am comfortable without close emotional relationships. It is very important to me to feel independent and self-sufficient, and I prefer not to depend on others or have others depended on me." The participants first select the statement that they most agree with, and then rate all four on a 7-point Likert scale (one equals not like me, seven equals very much like me). This questionnaire assesses how the participants ranked themselves on a secure, dismissing, fearful or preoccupied attachment style scale. In order to make an attachment style profile, the four category scores were created by splitting the median to determine if the participant had high or low aspects of that attachment style.

Rosenberg Self-Esteem Scale: The 10-item Rosenberg SelfEsteem Scale [11] was used to measure the participants' selfesteem. A sample item includes, "I take a positive attitude toward myself." Participants are asked to rate these items on a 4-point Likert scale (one equals strongly agree, four equals strongly disagree). A single score was determined by reverse scoring selected items and adding them to the scores of the remaining items as indicated by the instructions for using this instrument.

Alcohol Use Disorder Identification Test: The 10item Alcohol Use Disorder Identification Test [12] was used to determine the participants' habitual levels of alcohol consumption. Participants were asked about the frequency, quantity, and consequences of their drinking behavior. Each question was rated on different scales. A sample item includes "How many drinks containing alcohol do you have on a typical day when you are drinking?" with the answer choices of " 1 or 2," "3 or 4," "5 or 6," "7, 8, or 9," and "10 or more." Another sample item includes, "How often do you have six or more drinks on one occasion?" with the answer choices of "never," "less than monthly," "monthly," "weekly," and "daily or almost daily." A single score was determined by adding up the numbers associated with each answer option chosen as indicated in the instructions for the instrument. 
Modified Version of the Alcohol Use Disorder Identification

Test: This 10-item questionnaire was used to measure the participants' perceptions of their peers' alcohol use. This questionnaire was based off of the AUDIT; however, the researchers reworded the questions to change the subject to "the average college student" rather than the participant themselves. Participants were asked about their perceptions of the frequency, quantity, and consequences of their peers' drinking behavior. Each question was rated on different scales. A sample item includes "How many drinks containing alcohol do you think the average college student has on a typical day when he/she is drinking?" with the answer choices of " 1 or 2 ," "3 or 4 ," “5 or 6," “7, 8, or 9," and "10 or more". Another sample item includes "How often do you think the average college student has six or more drinks on one occasion?" with the answer choices of "never," "less than monthly," "monthly," "weekly," and "daily or almost daily." A single score was obtained in an identical manner as in the AUDIT.

Drinking Motivations Questionnaire-Revised: The 20item Drinking Motives Questionnaire-Revised [13] was used to measure motivations for alcohol consumption. The participants were asked to rate twenty drinking motivations using a 5-point Likert scale (one equals almost never/never, five equals almost always/always). A sample item includes "You drink to forget your worries." This test determines what level of social, coping, enhancement, or conformity motivations the participant reports for drinking. A score was obtained for each motivation (four scores in total) by adding the scores indicated for associated items.

\section{Procedure}

Before the study began, it was approved by the Institutional Review Board and received funding from an undergraduate faculty-mentored research grant. A link to the study was posted on Angelo State University's Sona-Systems website. Participants were able to select the study on Sona, and if they chose to participate, were linked to the study on Psychdata's (a secure research host site) website. When the participants selected the link to the study, they were presented with a consent form that assured them that all their responses would be kept confidential and that if the participants indicated on the surveys that they participated in any illegal activities (such as underage drinking) it would not be considered a confession of criminal activities. Next, the questionnaires were administered in the following order: section one of the Demographics Questionnaire, the RQ [10], the RSES [11] and the AUDIT [12], the modified version of the Alcohol Use Disorder Identification Test, the DMQR [13], and then section two of the Demographics Questionnaire. Finally participants were presented with a debriefing statement.

Results

An independent samples t-test was performed comparing participants who indicated that they had a highly Secure Attachment Style and participants who indicated they did not have a highly Secure Attachment Style. Individuals who scored themselves as highly Secure (M = 3.82, SD = 3.54, N = 66) did not have a reliably different score than those who scored themselves lowly ( $\mathrm{M}=4.65, \mathrm{SD}=5.13, \mathrm{~N}=82)$. Pearson bivariate correlations conducted on these data sets also did not find significant negative correlation in the relationship between a Secure Attachment Style and Alcohol Consumption $\mathrm{r}=-0.092, \mathrm{p}>.05$.

A Multivariate Analysis of Variance (Secure Attachment Style vs Dismissive Attachment Style vs Preoccupied Attachment Style vs Fearful Attachment style) was conducted on Social, Enhancement, Coping and Conformity Motivations for Alcohol Consumption. Wilks lambda indicated it as non-significant $\mathrm{F}$ $(4,127)=1.17, p>.05$. However, a significant univariate main effect was found for Enhancement Motivation $F(1,130)=4.63$, p $<.05$ (Figure 1). Participants who rated themselves as having a High Secure Attachment Style ( $M=12.27, S D=5.04)$ were more likely to consume alcohol for Enhancement Motivations than those who reported having a Low Secure Attachment Style (M $=10.60, \mathrm{SD}=5.08$ ). A significant main effect was also found in participants who reported they had both a High Secure and High Fearful Attachment Style with Coping Motivations ( $M=10.29$, $\mathrm{SD}=6.03) \mathrm{F}(1,130)=5.33, \mathrm{p}<.05$; Conformity Motivations $(\mathrm{M}=$ 8.79, $\mathrm{SD}=6.19) \mathrm{F}(1,130)=4.72, \mathrm{p}<.05$; and Social Motivations $(\mathrm{M}=15.71, \mathrm{SD}=6.66) \mathrm{F}=5.58, \mathrm{p}<.05$ for Alcohol Consumption.

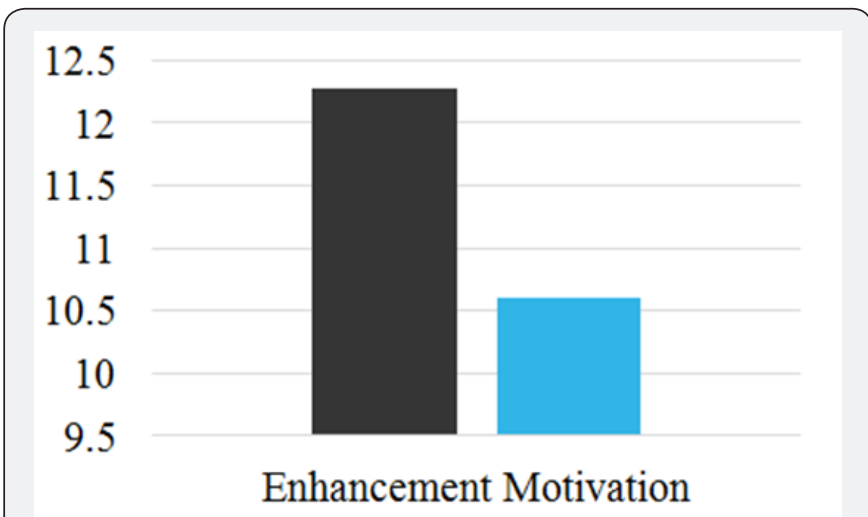

- High Secure Low Secure

Figure 1: MANOVA Results, $p>.05$.

Pearson Bivariate Correlation Analysis (Table 1) revealed that several relevant significant correlations exist between Motivations and levels of Alcohol Consumption. One of these relevant significant positive correlations was a moderate correlation between Social Motivations and Alcohol Consumption, $\mathrm{r}=.579, \mathrm{p}<.01$. Participants who were likely to report higher Social Motivations ( $M=13.45$, SD = 6.27) were also likely to report higher Alcohol Consumption ( $\mathrm{M}=4.27, \mathrm{SD}=$ 4.50). Another positive moderate correlation was found between Coping Motivations and Alcohol Consumption, $\mathrm{r}=.529, \mathrm{p}<.01$. Participants that were likely to report higher Coping Motivations $(M=9.43, S D=6.27)$ were also likely to report higher Alcohol Consumption $(\mathrm{M}=4.27, \mathrm{SD}=4.50)$. Additionally, a moderate 


\section{Psychology and Behavioral Science International Journal}

correlation was found between Enhancement Motivations and Alcohol Consumption, $\mathrm{r}=.549, \mathrm{p}<.01$. Participants who reported high levels of Enhancement Motivation ( $M=10.88, S D=5.07)$ were also likely to report higher levels of Alcohol Consumption.

Table 1: Correlations.

\begin{tabular}{|c|c|c|c|c|c|c|c|c|c|c|c|}
\hline & $\begin{array}{c}\text { Secure } \\
\text { Attachment } \\
\text { Style }\end{array}$ & $\begin{array}{c}\text { Fearful } \\
\text { Attachment } \\
\text { Style }\end{array}$ & $\begin{array}{l}\text { Preoccupied } \\
\text { Attachment } \\
\text { Style }\end{array}$ & $\begin{array}{l}\text { Dismissive } \\
\text { Attachment } \\
\text { Style }\end{array}$ & $\begin{array}{c}\text { Social } \\
\text { Motivation }\end{array}$ & $\begin{array}{c}\text { Coping } \\
\text { Motivation }\end{array}$ & $\begin{array}{c}\text { Enhancement } \\
\text { Motivation }\end{array}$ & $\begin{array}{l}\text { Conformity } \\
\text { Motivation }\end{array}$ & $\begin{array}{c}\text { Self } \\
\text { Esteem }\end{array}$ & $\begin{array}{c}\text { Personal } \\
\text { Alcohol } \\
\text { Use }\end{array}$ & $\begin{array}{c}\text { Perceived } \\
\text { Alcohol Use of } \\
\text { Others }\end{array}$ \\
\hline $\begin{array}{c}\text { Secure } \\
\text { Attachment } \\
\text { Style }\end{array}$ & 1 & $-.269 * *$ & -0.067 & -0.087 & -0.035 & -0.12 & 0.094 & -0.013 & 0.1 & -0.092 & -0.018 \\
\hline $\begin{array}{c}\text { Fearful } \\
\text { Attachment } \\
\text { Style }\end{array}$ & & 1 & -0.044 & -0.131 & 0.045 & 0.036 & -0.029 & 0.005 & $-.170^{*}$ & -0.029 & 0.002 \\
\hline $\begin{array}{l}\text { Preoccupied } \\
\text { Attachment } \\
\text { Style }\end{array}$ & & & 1 & $-.253^{* *}$ & 0.133 & 0.141 & $.167^{*}$ & 0.136 & -0.124 & 0.103 & 0.16 \\
\hline $\begin{array}{l}\text { Dismissive } \\
\text { Attachment } \\
\text { Style }\end{array}$ & & & & 1 & -0.129 & 0.01 & -0.023 & -0.053 & 0.107 & -0.138 & 0.034 \\
\hline $\begin{array}{c}\text { Social } \\
\text { Motivation }\end{array}$ & & & & & 1 & $.716^{* *}$ & $.796 * *$ & $.473^{* *}$ & -0.082 & $.579^{* *}$ & $.205^{*}$ \\
\hline $\begin{array}{c}\text { Coping } \\
\text { Motivation }\end{array}$ & & & & & & 1 & $.640^{* *}$ & $.564^{* *}$ & -0.07 & $.529^{* *}$ & $.202 *$ \\
\hline $\begin{array}{c}\text { Enhancement } \\
\text { Motivation }\end{array}$ & & & & & & & 1 & $.407^{* *}$ & -0.051 & $.549^{* *}$ & $.252^{* *}$ \\
\hline $\begin{array}{l}\text { Conformity } \\
\text { Motivation }\end{array}$ & & & & & & & & 1 & -0.096 & 0.16 & 0.077 \\
\hline Self Esteem & & & & & & & & & 1 & -0.022 & -0.003 \\
\hline
\end{tabular}

${ }^{*}$ Correlation significant at the .05 level (2-tailed)

${ }^{* *}$ Correlation Significant at the .01 level (2-tailed)

Social $(M=13.45, S D=6.27)$, Coping $(M=9.43, S D=6.27)$, and Enhancement Motivations ( $M=10.88, \mathrm{SD}=5.07$ ) were also weakly correlated to Estimated Alcohol Consumption of Peers $(\mathrm{M}=19.99, \mathrm{SD}=6.14)$. Participants who consumed alcohol due to Social Motivations estimated that their peers consumed slightly more alcohol in general $r=.205, \mathrm{p}<.05$. Participants who consumed alcohol due to Coping Motivations estimated that their peers consumed slightly more alcohol $r=.202$, $p<$ .05. Participants that indicated that they consumed alcohol for Enhancement Motivations estimated that in general their peers consumed slightly more alcohol $r=.252, p<.01$. However, there were no relevant correlations found between Attachment Styles and Estimated Alcohol Consumption of Peers.

Descriptive statistics reveal a large discrepancy between self-reported levels of Alcohol Consumption ( $\mathrm{M}=4.28, \mathrm{SD}=4.50)$ and Estimated Alcohol Consumption of Peers ( $M=19.99, \mathrm{SD}=$ 6.14). This means that, on average, the participants in this study estimated that their peers consumed 4.67 times the amount of alcohol that the participants admit to consuming. There is also a significant weak positive correlation between Alcohol Consumption and Estimated Alcohol Consumption of Peers, $r=$ $.208, p<.05$. There were no relevant correlations found between Motivating factors and Self Esteem. The only factor that was found to be correlated to Self-Esteem was a Fearful Attachment Style, $r=-.170, p>.05$. This finding is not relevant, however, because by definition a Fearful Attachment Style includes a negative model of self.

\section{Discussion}

The current findings were unable to establish a correlation between alcohol use and an insecure attachment style. This potentially could be because the majority of participants (75\%) were under the legal drinking age of twenty-one. It is possible that these scores could have been influenced by the fact that alcohol was not as available to these participants since they cannot obtain it legally. Another factor could have been socially desirable responding. The current researcher took precautions in order to reduce socially desirable responding by administering the questionnaires online and by clarifying in the IRB approved consent form that "any admission to illegal activity (such as underage drinking) does not mean that you confessed any criminal activity"; however, it is possible that socially desirable responding still occurred. Additionally, the results might not be representative of the entire population because $83.8 \%$ of participants were female. Globally, men tend to drink alcohol more frequently and consume more alcohol in one episode of drinking [14].

One previous and well-accepted theory (that was noted in the introduction) was that attachment style could directly affect motivation which leads to increased alcohol use. The current 
study, however, did not support this result. This research indicates that participants with insecure attachment styles were not more likely to consume alcohol for social or coping motivations. It did find that motivations were related to alcohol consumption without being related at all to attachment style. Interestingly enough, all of the motivations besides conformity were related to increased alcohol consumption. Conformity has been a major focus in many alcohol use prevention programs, so the current research could contribute to a better understanding of how to make these programs more effective.

Every participant in this study indicated that his or her peers consumed a substantial amount more than him or her which is consistent with other studies on this topic. One of the research questions this study sought out to answer was whether or not perceptions of peers drinking behavior varied based on attachment style, and according to these data the answer is no. However, this estimation was found to be correlated with other factors. Participants who consumed alcohol due to social, coping, or enhancement motivations were more likely to indicate that their peers consumed more alcohol than participants who did not indicate that they frequently used alcohol due to those motivations. Additionally, participants whose alcohol consumption score was higher indicated that they believed that their peers consumed more alcohol than the participants with low alcohol consumption scores.

Palfai et al. [1] research found a link between attachment styles with negative models of self and consuming alcohol for coping motivations. The current study set out to see if a direct correlation existed between self-esteem (which would be a negative model of self) and coping motivations if the other factors of the fearful and preoccupied attachment style were taken out of the picture. The current research did not find a relationship between these two factors. The researchers theorize that this link between coping motivations and fearful and preoccupied attachment styles is either due to an unknown tertiary factor or that the self-esteem measurement the current study used did not adequately measure the aspects of self-esteem that is correlated with consuming alcohol for coping motivations. The findings in this study are reflective of a college population, primarily of the students under the age of twenty-one due to convenience. Although the current study did not confirm the primary hypothesis, it did reveal several correlations with motivations.

\section{Future Directions}

In the future, this study should be repeated with college students over the age of 21 , with a more equal distribution in gender, and more measures in place to reduce socially desirable responding. If no link is established between attachment style and alcohol consumption in the repeated study then it could be concluded that the college population is an exception to the correlation found by other researchers. If the link between attachment style and alcohol consumption is established in the repeated study but the relationship between coping and social motivations is not established; then, more research should be conducted to determine the validity of the theory that the link is due to an evolutionary factor.

Additionally, more research should be conducted to determine how to best formulate an underage drinking prevention program. An experimental study should be conducted on conformity motivations to investigate if the lack of correlation found in this study is due to conformity not being a strong motivating factor for alcohol use or if the current peerpressure centered initiatives have been extremely effective in reducing the levels of conformity motivation in this generation of participants. Additionally, future research should craft and test the effectiveness initiatives focused on other motivations for alcohol consumption. Also, the link between estimated alcohol use of peers and personal alcohol use should be more closely examined to explore if a campus wide campaign dedicated to educating students about "college drinking norms" is effective in reducing levels of current alcohol consumption levels among students.

\section{Implications}

These data could have future implications in how campus wide responsible drinking campaigns are crafted. These implications could be seen not only in a college setting, but also in middle school and high school settings. If more effective underage drinking prevention programs are crafted and instituted in schools then there may be less alcohol related deaths in this demographic, fewer cognitive impairments, and fewer cases of alcohol dependence in adulthood, as these are all very serious consequences from underage drinking $[6,15]$.

Social workers, police officers, physicians, and parole officers may also find this information helpful in their respective professions. Alcohol dependence can lead to consequences that affect the whole community, so it is important that the people who typically work with individuals that have an AUD have a thorough understanding of all the factors contributing to potentially dangerous alcohol use. By understanding these factors better, these professional members of the community can better prevent individuals from reaching the point where they have an AUD or better help these individuals change their alcohol consumption habits.

Additionally, this research could have implications for parents or any other person concerned about a loved one's alcohol use. Identifying motivating factors of alcohol use can make the behavior seem more relatable and lead to increased empathy towards the individual instead of hostility. Empathy is viewed as a critical component to any helping relationship $[16,17]$. Moreover, by identifying an individual's personal motivations a personalized intervention may be conducted and alternate activities could be promoted that address the same motivations.

One can wonder why we were not born with this healthy hierarchy already established for us. Or perhaps we could just appreciate that at least we were born with the capacity to 
recognize our duality and the fix we are in,, and learn to evolve and complete our own development. Our unhealthy psyches function like inner and invisible wounds. To get well, we must heal these wounds. We need to take the proverbial bull by the horns, become pro-active and ongoing witnesses to the ongoing tug of war between our dueling psyches, and then choose which side were are going to fund, support, and strengthen. We also need to remember that all human beings have similar struggles with their duality. Learning to see ourselves and others with this double vision is at the heart of mindfulness and gives us a framework which can help us to understand ourselves better. It also guides us to see what we need to change in.

Our inner lives that will enable our outer lives to become better. We don't want to put a Band-Aid on our skin when our wounds are deep inside. We know that all healthy healing happens from the inside out. With mindfulness we learn how to utilize the healing powers of the healthy psyche to soothe and heal the wounds of the unhealthy psyche. We learn to acknowledge and tend to our unhealthy wounded psyches without letting them govern us. This in turn leaves us freer to live our lives governed by our truest inner nature which by its very nature is peaceful and joyous.

\section{References}

1. Mc Nally AM, Palfai TP, Levine RV, Moore BM (2003) Attachment dimensions and drinking-related problems among young adults: The meditational role of coping motives. Addictive Behaviors 28(6): 11151127.

2. De Rick A, Vanheule S, Verhaeghe P (2009) Alcohol addiction and the attachment system: An empirical study of attachmentstyle, alexithymia, and psychiatric disorders in alcoholic inpatients. Substance Use \& Misuse 44(1): 99-114.

3. Tops M, Koole SL, IJzerman H, Buisman Pijlman FT (2014) Why social attachment and oxytocin protect against addiction and stress: Insights from the dynamics between ventral and dorsal corticostriatal systems. Pharmacology, Biochemistry and Behavior 119: 39-48.

4. National Institute of Alcohol Abuse and Alcoholism (2016) Alcohol Facts and Statistics.
5. Bouchery EE, Harwood HJ, Sacks JJ, Simon CJ, Brewer RD (2011) Economic costs of excessive alcohol consumption in the US, 2006. American Journal of Preventive Medicine 41(5): 516-524.

6. National Institute of Alcohol Abuse and Alcoholism (2016) Underage Drinking.

7. Substance Abuse and Mental Health Services Administration (2013) Results from the 2012 national survey on drug use and health: Summary of national findings.

8. National Institute of Alcohol Abuse and Alcoholism (2015) College Drinking.

9. Martens MP, Page JC, Mowry ES, Damann KM, Taylor KK, et al. (2006) Differences between actual and perceived student norms: An examination of alcohol use, drug use, and sexual behavior. Journal of American College Health 54(5): 295-300.

10. Bartholomew K, Horowitz LM (1991) Attachment styles among young adults: A test of four-category model. Journal of Personality and Social Psychology 61(2): 226-244.

11. Rosenberg M (1965) Society and the adolescent self-image. Princeton University Press, New Jersey, USA.

12. World Health Organization (1992) Alcohol Use Disorder Identification Test.

13. Cooper ML (1994) Motivations for alcohol use among adolescents: Development and validation of a four-factor model. Psychological Assessment 6(2): 117-128.

14. Erol A, Karpyak VM (2015) Sex and gender-related differences in alcohol use and its consequences: Contemporary knowledge and future research considerations. Drug \& Alcohol Dependence 156: 1-13.

15. Quaglino V, De Wever E, Maurage P (2015) Relations between cognitive abilities, drinking characteristics, and emotional recognition in alcohol dependence: A preliminary exploration. Alcoholism: Clinical \& Experimental Research 39(10): 2032-2038.

16. Reynolds WJ, Scott B (1999) Empathy: A crucial component of the helping relationship. Journal of Psychiatric and Mental Health Nursing 6(5): 363-370.

17. Perkins HW, Meilman PW, Leichliter JS, Cashin JR, Presley CA (1999) Misperceptions of the norms for the frequency of alcohol and other drug use on college campuses. Journal of American College Health 47(6): 253-258.

\section{Your next submission with Juniper Publishers will reach you the below assets}

- Quality Editorial service

- Swift Peer Review

- Reprints availability

- E-prints Service

- Manuscript Podcast for convenient understanding

- Global attainment for your research

- Manuscript accessibility in different formats

( Pdf, E-pub, Full Text, Audio)

- Unceasing customer service

Track the below URL for one-step submission https://juniperpublishers.com/online-submission.php 